\section{Highly regioirregular polypropylene from asymmetric group 4 anilide(pyridine)phenoxide complexes $\dagger$}

\author{
Rachel C. Klet, David G. VanderVelde, Jay A. Labinger* and John E. Bercaw* \\ Received 19th April 2012, Accepted 9th May 2012 \\ DOI: $10.1039 / \mathrm{c} 2 \mathrm{cc} 32806 \mathrm{~b}$
}

Group 4 complexes containing an anilide(pyridine)phenoxide ligand and activated with methylaluminoxane (MAO) catalyze the formation of highly regioirregular polypropylene.

Polyolefins constitute one of the most important classes of commercial synthetic polymers, with annual worldwide capacity greater than 70 billion $\mathrm{kg} .{ }^{1}$ The past three decades have seen the development of soluble single-site olefin polymerization catalysts that span the transition metal series and allow access to previously unrealized polymer architectures. "Post-metallocene" olefin polymerization catalysts, in particular, have led to significant advances in living polymerization ${ }^{3}$ and to the preparation of olefin block copolymers. ${ }^{4}$

Our group has recently developed olefin polymerization catalysts based on group 4 metals supported by triaryl dianionic (XLX) pincer ligands; the ligand design takes advantage of the thermal stability of aryl-aryl bonds as well as versatile access to a wide variety of ligand scaffolds using cross-coupling chemistry. We have reported a series of heterocycle-linked bis(phenolate) ligands, where the heterocycle is pyridine (ONO), furan (OOO) or thiophene (OSO), which upon complexation with titanium, zirconium, hafnium and vanadium can give propylene polymerization precatalysts that exhibit good to excellent activities upon activation with methylaluminoxane (MAO). ${ }^{5}$ (We have also reported bis(anilide)pyridyl ligands (NNN), ${ }^{6}$ but their group 4 metal complexes exhibit poor activity for polymerization).

The ability of this triaryl dianionic ligand scaffold to adopt various geometries when coordinated to a metal, including $C_{2}$ and $C_{2 \mathrm{v}}$, suggested the possibility of stereoselective polymerization, based on well-established precedents with metallocene polymerization catalysts; however, the above catalysts afford primarily stereoirregular polypropylene. Hoping to gain further understanding of the fundamental processes governing microstructure control for these complexes, we decided to examine the effect of an asymmetric ligand. The architecture of the anilide(pyridine)phenoxide ligand (NNO) allows facile variation of substituents via

Arnold and Mabel Beckman Laboratories of Chemical Synthesis, California Institute of Technology, Pasadena, California 91125, USA. E-mail: bercaw@caltech.edu; Fax: 1-626-449-4159;

Tel: 1-626-395-6577

$\dagger$ Electronic supplementary information (ESI) available: Full experimental details and characterization data, with accompanying NMR spectra. CCDC 877737. For ESI and crystallographic data in CIF or other electronic format see DOI: 10.1039/c2cc32806b modular synthesis using cross-coupling reactions, including access to enantiopure catalysts for potential asymmetric applications by incorporation of a chiral group into the ligand. As a first target, we selected ligand 2, containing a chiral (1-phenylethyl)amine group.

Ligand 2 was synthesized as shown in Scheme 1. Selective monoarylation of 2,6-dibromopyridine with (3,5-di-t-butyl-2(methoxymethoxy)phenyl)pinacolborane, after careful screening of Suzuki coupling conditions, gave 2-bromo-6-(3,5-di-t-butyl-2(methoxymethoxy)phenyl)pyridine 1, which underwent a second Suzuki coupling with chiral 2-bromo- $N$-(1-phenylethyl)aniline (prepared according to a reported synthesis ${ }^{7}$ ) using a modified literature procedure. ${ }^{8}$ Deprotection with acidic THF afforded the desired asymmetric NNO ligand 2.

Reaction of $\mathbf{2}$ with tetrabenzylzirconium and tetrabenzylhafnium gave (NNO) $\mathrm{ZrBn}_{2} 3$ and $(\mathrm{NNO}) \mathrm{HfBn}_{2} 4$, respectively. The analogous reaction of $\mathbf{2}$ with tetrabenzyltitanium led to an inseparable mixture; however, reaction of 1 with $\mathrm{TiCl}_{2}\left(\mathrm{NMe}_{2}\right)_{2}$ yielded a related titanium complex, (NNO) $\mathrm{TiCl}_{2} \mathbf{5}$ (Scheme 2). Crystals of $\mathbf{5}$ suitable for X-ray diffraction were grown by slow vapor diffusion of pentane into a concentrated ether/dichloromethane solution; the X-ray structure reveals distorted trigonal bipyramidal geometry ${ }^{9}$ about titanium (Fig. 1).

Activation of complexes $\mathbf{3}$ and $\mathbf{5}$ with MAO in toluene or chlorobenzene solution, respectively, resulted in formation of
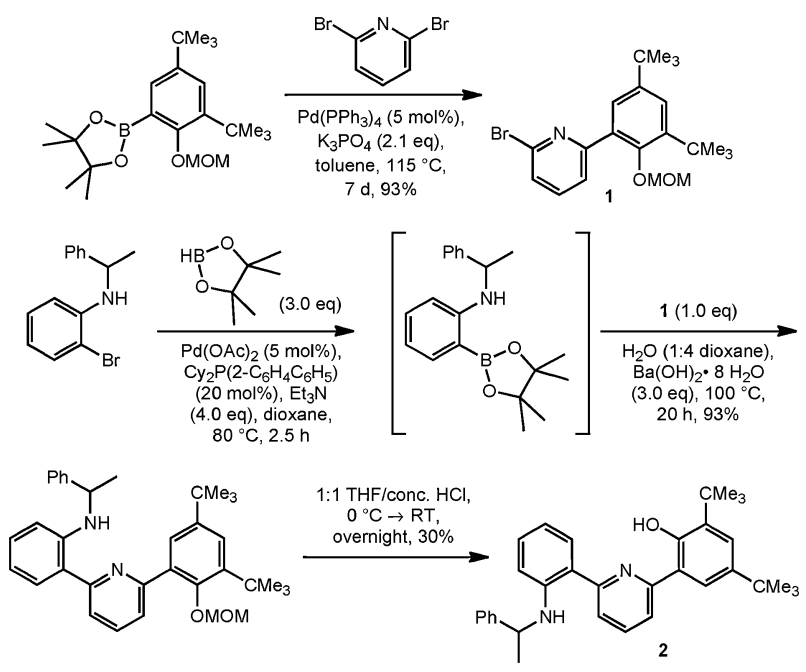

Scheme 1 Synthesis of anilide(pyridine)phenoxide ligand 2. 


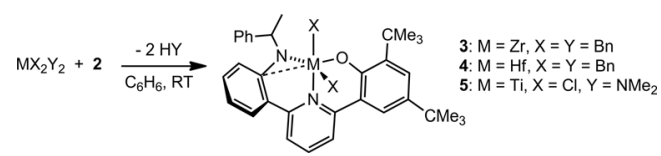

Scheme 2 Syntheses of metal complexes 3-5.

polypropylene (PP) under $5 \mathrm{~atm}$ propylene at $0{ }^{\circ} \mathrm{C}$ (Scheme 3$)$. (Somewhat surprisingly, the $\mathrm{Hf}$ analogue $\mathbf{4}$ showed no activity under these conditions; Hf is the most active group 4 metal for some types of post-metallocene catalysts. ${ }^{10}$ ) The activity of $\mathbf{3}$ was $1.7 \times 10^{4} \mathrm{~g} \mathrm{PP}(\mathrm{mol} \mathrm{cat})^{-1} \mathrm{~h}^{-1}$, while the Ti complex 5 was approximately an order of magnitude more active, at $1.5 \times$ $10^{5} \mathrm{~g}$ PP (mol cat $)^{-1} \mathrm{~h}^{-1}$. The activity of 5 remains the same after $3 \mathrm{~h}$ as after $30 \mathrm{~min}$ at $0{ }^{\circ} \mathrm{C}$, suggesting that the active species is relatively stable under polymerization conditions.

Gel permeation chromatograms (GPC) on the nonsticky elastomeric polypropylene polymers obtained from $\mathbf{3}$ and $\mathbf{5}$ show narrow molecular weight distributions, with $M_{w} / M_{n}$ of 1.8 and 1.5 , respectively, suggesting catalysis occurs at a single site. The $M_{n}$ values are higher for 5 than 3: 147000 and $26000 \mathrm{~g} \mathrm{~mol}^{-1}$ respectively. Thus with this ligand framework, $\mathrm{Ti}$ gives a better polymerization catalyst than $\mathrm{Zr}$, in terms of activity and polymer molecular weight.

${ }^{13} \mathrm{C}$ NMR spectroscopy was carried out to determine whether these $C_{1}$-symmetric precatalysts led to any degree of stereocontrol. Unexpectedly, we instead found that these catalysts make polypropylene with low regio- and stereocontrol. The ${ }^{13} \mathrm{C}$ NMR spectra of polypropylene obtained from $\mathbf{3}$ and $\mathbf{5}$ reveal a large number of 2,1-insertions; as many as 30-40\% of insertions may be inverted (Fig. 2). ${ }^{11}$ In contrast, primarily regioregular (and stereoirregular) polypropylene was obtained using the related bis(phenoxide)pyridyl (ONO) and bis(anilide)pyridyl (NNN) complexes previously reported by our group.,

We also sought to determine the presence of "3,1-insertions"$-\left(\mathrm{CH}_{2}\right)_{3}$ - groupings - which can result from $\beta$-hydride elimination and re-insertion in the opposite sense following a 2,1-insertion. Such a process would result in an excess of methylene groups; in its absence the ratio of $\mathrm{CH}: \mathrm{CH}_{2}: \mathrm{CH}_{3}$ groups would be $1: 1: 1 .{ }^{13} \mathrm{C}$ NMR spectroscopy alone is not able to determine

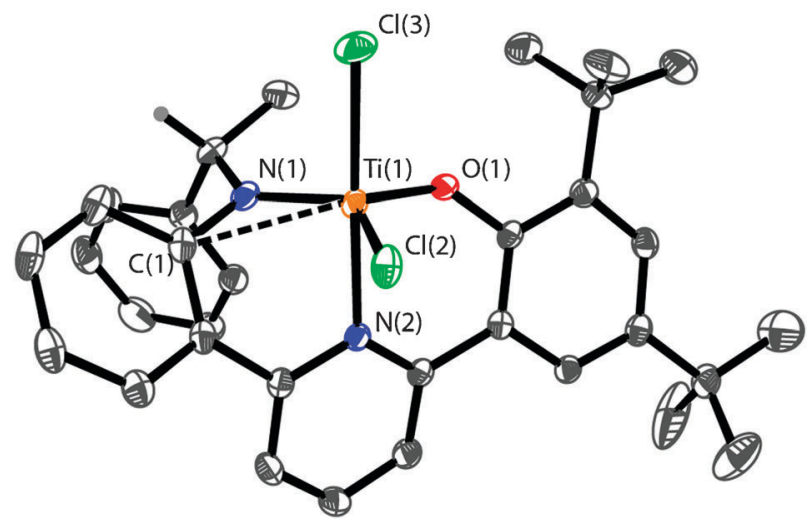

Fig. 1 Probability ellipsoid diagram (50\%) of the X-ray structure of 5. Selected bond lengths $(\AA)$ and angles $\left({ }^{\circ}\right)$ : $\mathrm{Ti}(1)-\mathrm{O}(1)=1.8040(17)$, $\mathrm{Ti}(1)-\mathrm{N}(1)=1.879(2), \quad \mathrm{Ti}(1)-\mathrm{N}(2)=2.153(2), \quad \mathrm{Ti}(1)-\mathrm{Cl}(2)=$ $2.3161(8), \quad \mathrm{Ti}(1)-\mathrm{Cl}(3)=2.3285(8), \quad \mathrm{Ti}(1)-\mathrm{C}(1)=2.609(2)$; $\mathrm{O}(1)-\mathrm{Ti}(1)-\mathrm{N}(1)=110.87(8), \quad \mathrm{O}(1)-\mathrm{Ti}(1)-\mathrm{Cl}(2)=118.49(6)$, $\mathrm{N}(1)-\operatorname{Ti}(1)-\mathrm{Cl}(2)=127.68(7)$.

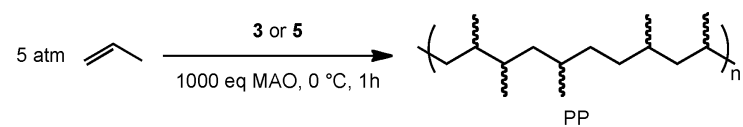

Scheme 3 Propylene polymerization catalyzed by $\mathbf{3}$ or $\mathbf{5}$.

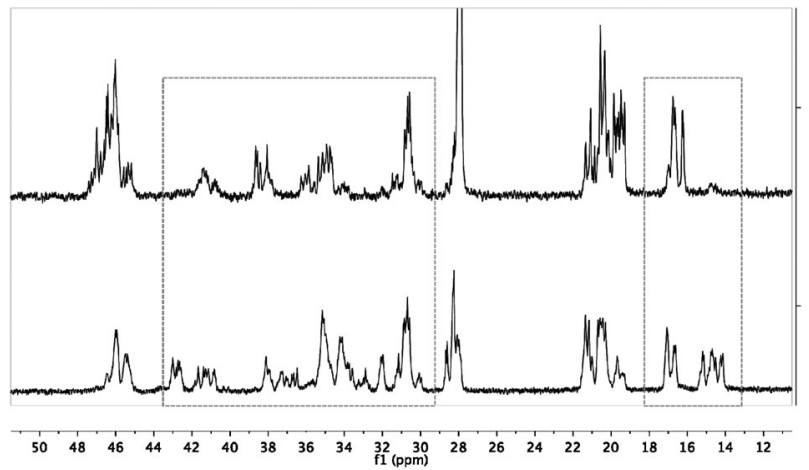

Fig. $2{ }^{13} \mathrm{C}$ NMR of PP from 3 (top) and 5 (bottom) at $120{ }^{\circ} \mathrm{C}$ in TCE- $d_{2}$. Regions indicating 2,1-insertions are highlighted.

the ratio, as the regions containing the signals for methine and methylene carbons are known to overlap. ${ }^{11}$ We performed 2D ${ }^{1} \mathrm{H}-{ }^{13} \mathrm{C}$ HSQC NMR spectroscopy on the PP obtained from 3 and 5; such experiments determine the proton connectivity of each ${ }^{13} \mathrm{C}$ signal, as well as the ${ }^{1} \mathrm{H}$ chemical shift of the associated protons. Although the methine and methylene signals do indeed overlap in the ${ }^{13} \mathrm{C}$ NMR spectra, all three types $\left(\mathrm{CH}, \mathrm{CH}_{2}\right.$ and $\left.\mathrm{CH}_{3}\right)$ are sufficiently separated in the ${ }^{1} \mathrm{H}$ NMR spectra to allow their relative abundance to be determined by integration. In fact, we observe a $1: 1: 1$ ratio for $\mathrm{CH}: \mathrm{CH}_{2}: \mathrm{CH}_{3}$, which suggests that there is little or no 3,1insertion, only $1,2-$ and $2,1-$, during propylene polymerization. ${ }^{12}$

For early transition metal metallocene catalysts 1,2-insertion is typically favored by both electronic and steric factors; competing 2,1 -insertion is usually quite rare, on the order of $<1 \mathrm{~mol} \%{ }^{13}$ There are examples of post-metallocene catalysts that appear to propagate exclusively via a 2,1-insertion mechanism, ${ }^{14}$ but to the best of our knowledge this is the only early metal catalyst that shows so little apparent preference for 1,2- vs. 2,1-insertions; ${ }^{15}$ such low regiocontrol is more commonly observed with late metal polymerization catalysts that can undergo "chain running". ${ }^{16}$ A half-metallocene system was reported to incorporate 2,1-insertions on the order of $10 \%$ at $25{ }^{\circ} \mathrm{C}$ (the percentage decreased at lower temperatures). The relative steric openness of the system was offered as a possible explanation for the higher frequency of inversion relative to metallocene polymerization catalysts. ${ }^{17}$ In our case, the (NNO) catalysts $\mathbf{3}$ and $\mathbf{5}$ are sterically very similar to their symmetric (ONO) and (NNN) analogues, which exhibit no such regioirregularity, ${ }^{5,6}$ suggesting that some factor other than simple sterics may control regioselectivity in these post-metallocene polymerization catalysts. One possibility might be dissociation of the anilide arm, perhaps facilitated by MAO, to yield a fluxional active species that has variable regioselectivity depending on the position of the labile anilide arm. (Note that the anilide $\mathrm{N}$ does not lie in the $\mathrm{O}-\mathrm{N}$ (pyridine)-Ti plane; such a distortion could signal heightened lability). Work is ongoing to elucidate the origin of the unusual polymer microstructure generated with these asymmetric post-metallocene group 4 metal catalysts. 
The authors gratefully acknowledge the USDOE Office of Basic Energy Sciences (DE-FG03-85ER13431 to JEB) for funding. An NSF-GRF to RCK is gratefully acknowledged. We thank Dr Jo Ann Canich (ExxonMobil) for obtaining GPC data and Lawrence Henling and Dr Loi H. Do for help obtaining crystallographic data.

\section{Notes and references}

1 P. D. Hustad, Science, 2009, 325, 704.

2 V. C. Gibson and S. K. Spitzmesser, Chem. Rev., 2003, 103, 283.

3 G. J. Domski, J. M. Rose, G. W. Coates, A. D. Bolig and M. Brookhart, Prog. Polym. Sci., 2007, 32, 30; A. M. Anderson-Wile, J. B. Edson and G. W. Coates, in Complex Macromolecular Architectures, John Wiley \& Sons (Asia) Pte Ltd, Singapore, 2011, pp. 267-316.

4 D. J. Arriola, E. M. Carnahan, P. D. Hustad, R. L. Kuhlman and T. T. Wenzel, Science, 2006, 312, 714.

5 T. Agapie, L. M. Henling, A. G. DiPasquale, A. L. Rheingold and J. E. Bercaw, Organometallics, 2008, 27, 6245; S. R. Golisz and J. E. Bercaw, Macromolecules, 2009, 42, 8751 .

6 I. A. Tonks, D. Tofan, E. C. Weintrob, T. Agapie and J. E. Bercaw, Organometallics, 2012, 31, 1965.

7 F. M. Rivas, U. Riaz, A. Giessert, J. A. Smulik and S. T. Diver, Org. Lett., 2001, 3, 2673.

8 O. Baudoin, D. Guénard and F. J. Guéritte, J. Org. Chem., 2000, 65, 9268; A. S. Rebstock, F. Mongin, F. Trécourt and G. Quéguiner, Org. Biomol. Chem., 2003, 1, 3064.

9 The $\operatorname{Ti}(1)-\mathrm{C}(1)_{\text {ipso }}$ bond length of 2.609(2) A may be suggestive of an ipso interaction. See ref. 6 .

10 See for example: T. R. Boussie, G. M. Diamond, C. Goh, K. A. Hall, A. M. LaPointe, M. Leclerc, C. Lund, V. Murphy, J. A. W. Shoemaker, U. Tracht, H. Turner, J. Zhang, T. Uno, R. K. Rosen and J. C. Stevens, J. Am. Chem. Soc., 2003, 125, 4306;
K. A. Frazier, R. D. Froese, Y. He, J. Klosin, C. N. Theriault, P. C. Vosejpka, Z. Zhou and K. A. Abboud, Organometallics, 2011, 30, 3318.

11 For full assignment of the ${ }^{13} \mathrm{C}$ NMR of PP from 5 see ESI. $\dagger$ For ${ }^{13} \mathrm{C}$ NMR assignment of 2,1-insertions see: T. Asakura, Y. Nishiyama and Y. Doi, Macromolecules, 1987, 20, 616; A. Grassi, A. Zambelli, L. Resconi, E. Albizzati and R. Mazzocchi, Macromolecules, 1988, 21, 617; H. N. Cheng and J. A. Ewen, Makromol. Chem., 1989, 190, 1931; T. Asakura, N. Nakayama, M. Demura and A. Asano, Macromolecules, 1992, 25, 4876; Z. Zhou, J. C. Stevens, J. Klosin, R. Kummerle, X. H. Qiu, D. Redwine, R. J. Cong, A. Taha, J. Mason, B. Winniford, P. Chauvel and N. Montanez, Macromolecules, 2009, 42, 2291.

12 See ESI $\dagger$ for $2 \mathrm{D}{ }^{1} \mathrm{H}-{ }^{13} \mathrm{C}$ HSQC NMR data and integration of ${ }^{1} \mathrm{H}$ NMR spectra.

13 V. Busico, R. Cipullo, J. C. Chadwick, J. F. Modder and O. Sudmeijer, Macromolecules, 1994, 27, 7538.

14 P. D. Hustad, J. Tian and G. W. Coates, J. Am. Chem. Soc., 2002, 124, 3614 .

15 Resconi has reported a zirconocene catalyst that polymerizes propylene with 2,1-insertions on the order of $3 \mathrm{~mol} \%$ : L. Resconi, I. Camurati and O. Sudmeijer, Top. Catal., 1999, 7, 145. A $\mathrm{Ti}$ thio(bisphenoxy) complex has been reported by Miyatake et al. that gives a regioirregular polypropylene (the $\mathrm{mol} \%$ of 2,1 -insertions was not reported): T. Miyatake, K. Mizunuma and M. Kakugo, Makromol. Chem., Macromol. Symp., 1993, 66, 203.

16 For exemplary ${ }^{13} \mathrm{C}$ NMR of polypropylene from a late-metal catalyst see: E. F. McCord, S. J. McLain, L. T. J. Nelson, S. D. Arthur, E. B. Coughlin, S. D. Ittel, L. K. Johnson, D. Tempel, C. M. Killian and M. Brookhart, Macromolecules, 2001, 34, 362.

17 S. W. Ewart, M. J. Sarsfield, D. Jeremic, T. L. Tremblay, E. F. Williams and M. C. Baird, Organometallics, 1998, 17, 1502. 